\title{
DURABILITY STUDY OF CONCRETE WITH ELECTRONIC WASTE PLASTIC AGGREGATE
}

Scientific paper

\section{Alena Sičáková}

(Received: 20 November 2020; accepted: 20 June 2021)

Technical University of Košice, Slovakia, Faculty of Civil Engineering, Assoc. Prof.

Corresponding author: alena.sicakova@tuke.sk

\section{Erika Figmigová}

Technical University of Košice, Slovakia, Faculty of Civil Engineering, MSc., PhD. Candidate

\begin{abstract}
This study aims to determine the durability of concrete, in which plastic chips originating from the casing and enclosures of small electronic items are used as a part of coarse natural aggregate. The following three amounts were used: $50 \%, 70 \%$, and $90 \%$ of the aggregate by volume. The concretes were tested after 28 days of standard curing as well as after exposure to physical ( 25 freeze-thaw cycles and 25 wet-dry cycles) and chemical $\left(\mathrm{HCl}, \mathrm{MgSO}_{4}\right.$, and $\left.\mathrm{NaOH}\right)$ aggressive influences. Durability was evaluated based on changes in both flexural and compressive strength after exposure. The results of the corrosion resistance tests confirm the different types of behavior of the samples, depending on the relative proportion of the plastic aggregate. In terms of a comprehensive evaluation of the experiment, the greatest potential was found in concrete with $50 \%$ plastic chips, which can be defined as lightweight-low strength concrete. However, the specific compressive strength (strength to density ratio) increased with increasing amounts of plastic aggregate, which is a good standpoint for recycling this waste if specific applications are identified that can accept the technical limits of this material while using the positive parameters that could be useful for the application.
\end{abstract}

Keywords: Electronic waste plastic aggregate (EWPA); durability; freeze-thaw resistance; wet-dry resistance; chemical resistance. 


\section{INTRODUCTION}

In the past few decades, there has been significant consumption of plastic products worldwide, which has contributed to the high production of plastic waste [1]. Many plastic products, such as PET bottles, are only used for a short period. Many experimental studies have focused on the use of plastic waste as an alternative raw material in mortar or concrete mixtures. In their study, the authors used plastic waste in two forms: fibers [2-4] and aggregates (granules, chips, etc.) [5-10]. The types of plastics are polyethylene terephthalate (PET), polyvinylchloride (PVC), low-density polyethylene (LDPE), and high-density polyethylene (HDPE) [1].

The application of plastic waste in the form of fibers was addressed by Bui et al. [2]. Fibers prepared from PET bottles (RPET) and woven plastic sacks (RWS) were used for reinforcing recycled aggregate concrete (RAC). They found that RPET fibers performed better than RWS fibers. Both RWS and RPET fibers improved the postcracking behavior and ductility capacity of RAC, as well as the splitting tensile strength and shear strength. The fibers resulting from cutting PET bottles were also studied by Al-Hadithi et al. [3]. They attempted to detect the properties of self-compacting concrete (SCC) by adding these fibers. The results of the test showed that the plastic fibers have an adverse effect on the fresh properties of the SCC, but an improvement in the hardened properties was observed. Pešić et al. [4] studied the application of high-density polyethylene (HDPE) fibers; their source was a mixed stock, including various post-consumer wastes (mainly home appliances). They found that the compressive strength and modulus of elasticity of concrete did not improve with the addition of HDPE fibers, while flexural toughness, water permeability, and early plastic shrinkage significantly improved.

The application of plastic waste as a plastic aggregate (PA) was studied by Safi et al. [5]. They focused on recycled PET coming from bags, manufactured as fine aggregate, in the production of self-compacting mortars instead of sand. The sand was replaced with recycled PET at weight amounts of $0 \%, 10 \%, 20 \%, 30 \%$, and $50 \%$. The results of the mechanical tests showed that the compressive strength at 28 days of self-compacting mortar containing up to $50 \%$ of plastic waste was acceptable for lightweight mortars with a bulk density of $1500 \mathrm{~kg} \cdot \mathrm{m}^{-3}$. The reduction in the compressive strength was between $15 \%$ and $33 \%$ for mortars containing $20 \%-50 \%$ plastic waste. PET granules were also used by Albano et al. [6]. They studied the mechanical behavior of concrete and found that concrete mixtures containing PET granules showed a reduction in compressive strength, splitting tensile strength, and modulus of elasticity.

Kou et al. [7] investigated the properties of fresh and hardened concrete, which were prepared using recycled plastic waste sourced from scrapped PVC pipes to replace river sand as fine aggregates. River sand was partially replaced by PVC granules in percentages of $0 \%, 5 \%, 15 \%, 30 \%$, and $45 \%$ by volume. They found that the workability, density, compressive strength, and splitting tensile strength of lightweight aggregate concrete were reduced, while the ductility, drying shrinkage, and resistance to chloride ion penetration were improved. The authors stated that the optimal replacement percentage should be within $15 \%$ by volume.

Gregorova et al. [8] presented the properties of lightweight concrete containing expanded polystyrene (EPS), PVC cables and ethylene vinyl acetate granules. These aggregates were applied in different percentages, having a positive effect on the thermal properties of the concrete. The highest strength values were achieved by samples using EPS and EVA as well as EVA and PVC cables in a ratio of 1:1. Yang et al. [9] focused on the study of selfcompacting lightweight concrete (SCLC), which contained recycled modified polypropylene plastic particles (PP). The following four replacement levels of sand by volume were introduced: $0 \%, 15 \%, 20 \%$, and $30 \%$. The slump flow value improved with an increase in the plastic content, whereas the slump loss was reduced; however, the tendency of bleeding was detected when the replacement level reached $30 \%$. The viscosity of SCLC was reduced when the sand replacement level was increased by up to $15 \%$. The compressive strength, splitting tensile strength, and flexural tensile strength were improved by increasing the plastic content up to $15 \%$.

Kan and Demirboğa [10] investigated the effects of using recycled, thermally modified, waste expanded polystyrene foam (MEPS) as a potential aggregate in lightweight concrete. MEPS aggregate was used as a replacement for natural aggregate at levels of $0 \%, 25 \%, 50 \%, 75 \%$, and $100 \%$ by volume. While using MEPS in concrete as an aggregate, the properties of concrete improved, but others were also negatively affected. A high amount of MEPS reduces the density of the concrete and, accordingly, the compressive strength. However, a 28day compressive strength in the range of $12.58 \mathrm{MPa}$ to $23.34 \mathrm{MPa}$ was considered to meet the strength requirements of semi-structural lightweight concrete.

Wu et al. [11] studied the effect of recycled polytetrafluoroethylene (PTFE) on the physical and mechanical properties of concrete. For this purpose, recycled plastic concrete with $0 \%, 3 \%, 5 \%$, and $7 \%$ of the mass proportion Sičáková, A, Figmigová, E 
of cement were designed. The addition of PTFE to concrete increased its strength [11]. The compressive strength and splitting tensile strength reached their best values when the PTFE content was $5 \%$ in the 7-day-and 28-day curing ages of concrete.

The chips from the casing and enclosures of small electronic items, such as keyboards, TVs, monitors, refrigerators, and microwave ovens, constitute another group of plastic waste. Authorized entities operate equipment that disassembles electrical and electronic appliances into individual components. Metals, printed circuit boards, plastics, glass, and other materials are separated and handled individually. The separated plastics were further processed and crushed into various fractions in plastic waste shredders. Because the casing parts of these electrical appliances are made of different plastics, the waste shred is specific, in that it is a mixture of different types of plastics with different properties. The following kinds have the largest share in mixtures: polyethylene (PE), polystyrene (PS), polypropylene (PP), polyvinyl chloride (PVC), and acrylonitrile-butadiene-styrene (ABS). These plastics are nonbiodegradable and represent a significant environmental burden. However, they have the potential to be used as aggregates in building mixtures in the form of particles (grains, chips, flakes, etc.).

It is relatively difficult to trace research into this type of plastic waste because, in the study of the sources, we found that the authors of the works are not very consistent in their characterization of waste from electronics in general. Many authors use the term e-waste, but on closer inspection, we can see that this term is also used for waste containing other parts of electronics, such as glass or metal elements. Whether in the introduction to the article, or in the description of their own experiment, the authors often do not specify exactly the composition or type of e-waste it is. We attribute this shortcoming and lack of clarity in the current articles to the fact that this is a relatively young area of research, and the nomenclature and characteristics of this type of waste are not firmly entrenched. At best, waste is referred to as e-waste plastic (EWP). Here, a large part of the publications deals with separated electronic printed circuit boards (PCBs), free of metal strips, and crushed. Therefore, it is a crumb that is not a mixture of several types of plastics. In this category, it is possible to observe a significant research activity for use in concrete and other building mixtures as a substitute for aggregates [12-15]. The authors state that in the past decade, the production of e-waste has increased because of the increase in the use of electronic components to a greater extent. A large quantity of damaged PCBs is discarded in the environment without proper recycling treatment in many places.

Only a few studies have identified plastics from the casing and enclosures of small electronic items in their research. Ashwini [16] identified e-waste components as follows: cathode ray tubes, PCBs, chips, and other goldplated components, plastics, and computer wires. This means that the author separated the PCBs from other plastics that were under investigation. EWP as fine and coarse aggregates in concrete with percentage replacements of $0 \%, 10 \%, 20 \%$, and $30 \%$ was studied [16]. Based on the results, plastics can be used to replace some aggregates in a concrete mixture. This would contribute to the reductions in the unit weight of the concrete as well as the strength, which would allow it to be used in applications requiring non-bearing lightweight concrete. An experimental study on the utilization of EWP particles as coarse aggregates in concrete with a percentage replacement ranging from $0 \%$ to $25 \%$ of the weight of coarse aggregate was conducted by Lakshmi and Nagan [17]. They found that with waste plastic content up to $12 \%$, the addition of e-plastic aggregate did not significantly reduce the compressive strength and split tensile strength. The reduction was more significant with higher amounts of plastic. The application of fly ash has been found to be useful in improving strength properties.

The advantages of using EWP in concrete are as follows [16]: extreme versatility and ability to be tailored to meet specific technical needs; lighter weight than competing materials, which reduces fuel consumption during transportation; durability and longevity; resistance to chemicals, water, and impact; excellent thermal and electrical insulation properties; comparatively lower production cost; and increase in the bonding capacity with an increase in temperature at the melting point. The main disadvantages are as follows: low bonding properties, which influence the quality of the interfacial transition zone, which affects the strength parameters of concrete and a low melting point, so that it cannot be used in furnaces. According to Awoyera and Adesina [18], there are some limitations to the application of plastic waste, including a lack of understanding and a lack of standards.

Looking at the overview of the presented works focused on testing PA into concrete or mortar, in addition to the properties of fresh mixtures, they focus on testing the mechanical properties, while the impacts are not unambiguous, as the authors [15-18] report both improvement and deterioration. Research on resistance to direct aggressive action is presented to a lesser extent. Saikia and de Brito summarized studies on testing for shrinkage, water absorption, gas permeability, and microstructure in their review article [19]. This study presents the results of the application of EWP in concrete in amounts of $50 \%, 70 \%$, and $90 \%$ of natural aggregate by volume. The testing

Sičáková, A, Figmigová, E 
of samples focused on durability parameters, in terms of physical and chemical effects. Based on the experimental results, the relationships for predicting the durability of concrete were defined in terms of the dependence between strength before and after aggressive exposure. Therefore, this article presents a comprehensive study devoted to durability-related properties.

\section{MATERIALS AND METHODS}

\subsection{Materials}

The following materials were used for the experiment:

Binder: $\quad$ Portland cement CEM II/A-S 42.5

Additive: fly ash from electric plant

Admixure: polycarboxylate-type water reducer (WR)

Aggregates: - natural aggregate 0/4 (NA), with $70 \%$ of the $0 / 2$ fraction

- E-waste plastic aggregate (EWPA)-plastic scrap from the casing and enclosures of small electronic items in the form of chips (Fig. 1). The grain size is shown in Fig. 2, and it is compared with the limit values recommended by STN EN 206 (national annex) [20] for mixtures with $D_{\max }=$ $8 \mathrm{~mm}$. In total, the waste grains are in the range of $1-8 \mathrm{~mm}$, with a substantial part of the grains being the $4 / 8$ fraction (84\%). The remainder was represented by fractions $1 / 2(5 \%)$ and $2 / 4(11 \%)$. For use in concrete, this grain size distribution would be unsuitable because of the lack of fines. The physical parameters of the aggregates are listed in Tab. 1.

Table 1 Physical parameters of aggregates

\begin{tabular}{cccc}
\hline & Density & Bulk density & Void content \\
& {$\left[\mathrm{kgm}^{-3}\right]$} & {$\left[\mathrm{kgm}^{-3}\right]$} & {$[\%]$} \\
\hline Natural aggregate & 2590 & 1860 & 28.0 \\
E-waste plastic aggregate & 960 & 610 & 36.5 \\
\hline
\end{tabular}

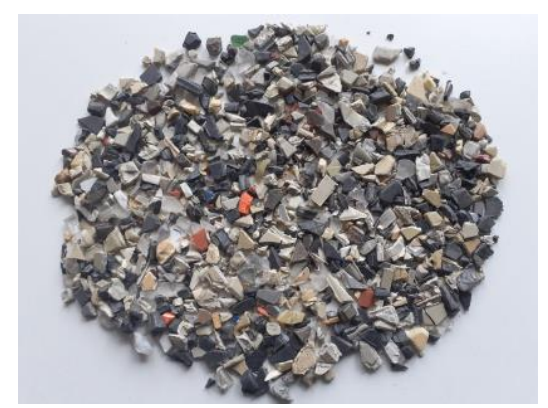

Figure $1 \mathrm{E}$-waste plastic aggregate

\subsection{Methods}

The principle of the experiment lies in the replacement of natural aggregates with EWPA in different volume ratios, as well as durability testing under various physical and chemical aggressive conditions. The specifics of EWPA were considered by optimizing the grain size by adding NA fraction 0/4, which contained $70 \%$ fraction $0 / 2$. Calculating the grain sizes revealed that EWPA/NA ratio of 50/50 resulted in an acceptable grain size, as shown in Fig. 2. However, to study the possibilities of EWPA, mixtures with a higher proportion of EWPA (70/30 and 90/10) were also included in the experimental program, while the total volume of the binder remained the same. These mixtures are close in structure to the so-called monofractive concrete, with a significantly low proportion of fine aggregates. Basha et al. [21] and Choi et al. [22] also investigated a similar high content of PA (up to 75\%). The volume ratio of aggregate to binder $a / b=0.6: 0.4 \mathrm{~m}^{3}$, as well as the water-to-binder ratio $\mathrm{w} / \mathrm{b}=0.35$, remained the same in all mixtures. With an increase in NA, the consistency was controlled by increasing the dose of the water 
reducer. The recipes are listed in Tab. 2. Subsequently, the test specimens were produced with a beam shape of $40 \times 40 \times 160 \mathrm{~mm}$. Samples were taken from the molds after $24 \mathrm{~h}$ of curing under standard water storage in accordance with STN EN 12390-2 [23]. Samples with different proportions of EWPA are shown in Fig. 3.

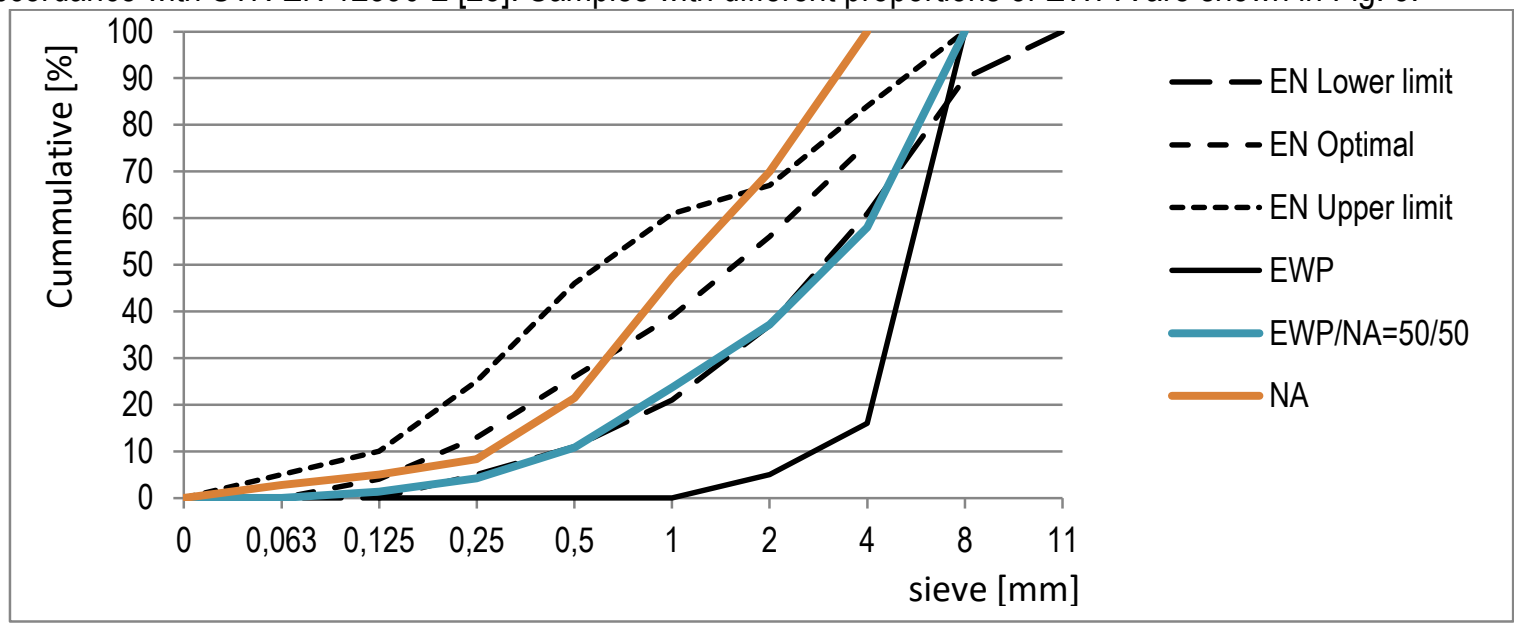

Figure 2 Grain-size distribution of aggregates compared with standard curves recommended by [20]

Table 2 Concrete mixtures according to EWPA/NA ratio

\begin{tabular}{|c|c|c|c|c|c|c|c|c|}
\hline \multirow{2}{*}{$\begin{array}{c}\text { EWPA/NA } \\
\text { [vol.\%] }\end{array}$} & \multicolumn{2}{|c|}{ EWPA } & \multicolumn{2}{|c|}{ NA } & \multirow{2}{*}{$\begin{array}{c}\text { Cement } \\
{[\mathrm{kg}]}\end{array}$} & \multirow{2}{*}{$\begin{array}{c}\text { Fly ash } \\
\text { [kg] }\end{array}$} & \multirow{2}{*}{$\begin{array}{c}\text { Water } \\
\text { [l] }\end{array}$} & \multirow{2}{*}{$\begin{array}{l}\text { WR } \\
\text { [\%] }\end{array}$} \\
\hline & {$[\mathrm{kg}]$} & {$\left[\mathrm{m}^{3}\right]$} & [kg] & {$\left[\mathrm{m}^{3}\right]$} & & & & \\
\hline $0 / 100$ & - & 0.0 & 1555 & 0.6 & & & & 0.7 \\
\hline $50 / 50$ & 290 & 0.3 & 780 & 0.3 & & & & 0.5 \\
\hline $70 / 30$ & 400 & 0.42 & 465 & 0.18 & 400 & 160 & 196 & 0.5 \\
\hline $90 / 10$ & 520 & 0.54 & 155 & 0.06 & & & & 0 \\
\hline
\end{tabular}
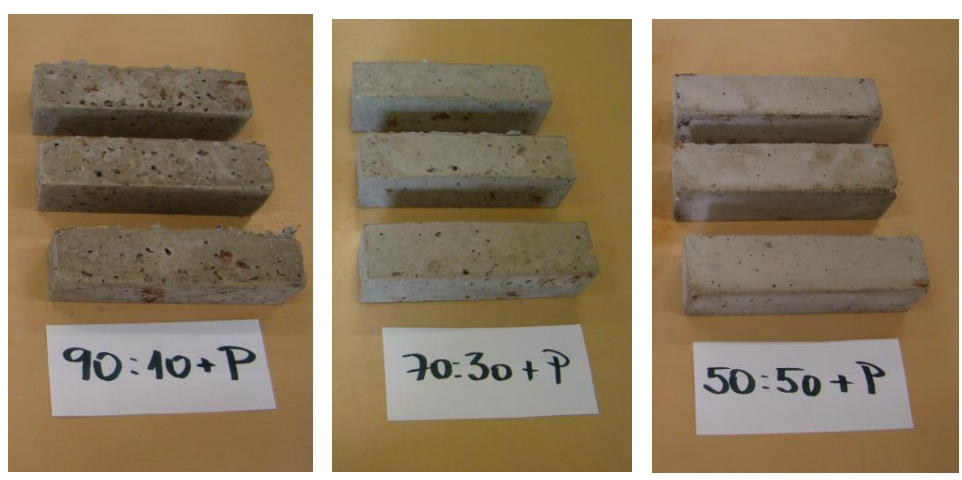

Figure 3 Samples with EWPA after 28 days of curing

After 28 days of curing, one series of samples was subjected to the measurement of the physico-mechanical properties, including:

- density according to STN EN 12390-7 [24]

- flexural strength, and

- compressive strength, both according to STN EN 196-1 [25]

Other series (each containing three specimens) were subsequently exposed to aggressive environments in accordance with the following methodologies:

\section{- $\quad$ Freeze-thaw cycles.}

A modified method was used to evaluate the resistance to freezing and thawing with respect to the specification of the cycle. It was based on the 'slab test' method ( $24 \mathrm{~h}$ cycle duration while the temperature shall Sičáková, A, Figmigová, E 
exceed $0{ }^{\circ} \mathrm{C}$ for at least $7 \mathrm{~h}$ but no more than $9 \mathrm{~h}$ during each cycle) [26], as well as ASTM C666, Procedure $\mathrm{B}$ (Freezing in air and thawing in water), which requires the thawing time to be at least $20 \%$ of the cycle duration [27]. In our experiment, one cycle consisted of freezing at $-20 \pm 2{ }^{\circ} \mathrm{C}$ for $16 \mathrm{~h}$ and thawing at $+20 \pm 2{ }^{\circ} \mathrm{C}$ for $8 \mathrm{~h}$. The freezing and thawing regimens were then performed in accordance with a national standard based on testing of water-saturated samples, with freezing taking place in air and thawing in water. Sample testing was terminated after 25 cycles.

\section{- Wet-dry cycles}

This is a less commonly used methodology, but it is extremely informative in terms of reflecting the most common destructive effects to which the structure may be subjected. When the material is soaked, it swells (increases in volume); when the material dries, it shrinks (decreases in volume). These volume changes can cause a gradual disruption in the structure and a decrease in the mechanical properties. The exact methodology of individual wetting and drying cycles is not uniform. The dry and wet circulation methods adopted by various researchers are different without a uniform theoretical basis, and there is no standard to follow, as also presented by Guo et al. [28]. This method is more commonly used to accelerate the rate of chemical attacks, such as sulfate attacks, on the erosion performance of concrete [28-31]. However, the process itself, which involves immersing only the samples in water, has a significant aging effect. The cycle may be modified depending on the specific purpose of the test; one cycle represents the drying-cooling-soaking of the sample. For example, one cycle according to He et al. [29] consists of drying at $+60 \pm 2{ }^{\circ} \mathrm{C}$ for $21 \mathrm{~h}$, air cooling at $+20 \pm 2{ }^{\circ} \mathrm{C}$ for $3 \mathrm{~h}$, and soaking in water at $20 \pm 2^{\circ} \mathrm{C}$ for $24 \mathrm{~h}$. Our procedure was specified to run one cycle in $24 \mathrm{~h}$, that is,

- drying at $+60^{\circ} \mathrm{C} \pm 2{ }^{\circ} \mathrm{C}$ for $15 \mathrm{~h}$

- air cooling at $+20^{\circ} \mathrm{C} \pm 2{ }^{\circ} \mathrm{C}$ for $1 \mathrm{~h}$ and

- $\quad$ soaking in water at $20^{\circ} \mathrm{C} \pm 2{ }^{\circ} \mathrm{C}$ for $8 \mathrm{~h}$

The samples were tested after 25 cycles because of their conditions. After the 25th cycle of alternating freezing and thawing, as well as wetting and drying, both the flexural and compressive strengths were determined, and the percentage changes compared to the control samples were recorded.

\section{- $\quad$ Aggressive chemical exposure.}

The resistance of the mixtures with EWPA to three types of chemically aggressive environments was tested.

- $\quad$ acidic environment: $0.5 \% \mathrm{HCl}$ solution $(\mathrm{pH}=2.0)$

- $\quad$ alkaline environment: $1 \% \mathrm{NaOH}$ solution $(\mathrm{pH}=11.5)$

- $\quad$ sulfate-magnesium environment: $5 \% \mathrm{MgSO}_{4}$ solution $(\mathrm{pH}=7.1$ )

The samples were stored for 60 days at complete immersion under static conditions. Subsequently, the flexural and compressive strengths were determined, and the percentage changes relative to the control samples were determined.

\section{RESULTS AND DISCUSSION}

\subsection{Results of 28-day properties}

The resultant values of the control samples, that is, after 28 days of curing and before being exposed to aggressive environments, are shown in Fig. 4 for mutual comparison.

Based on the resultant bulk densities $\left(\rho_{v}=1350-1720 \mathrm{~kg} \cdot \mathrm{m}^{-3}\right)$, the samples with EWPA belong to lightweight concrete in accordance with STN EN 206-classification $\left(\rho_{v}<2000 \mathrm{~kg} \cdot \mathrm{m}^{-3}\right)$ [20]. As expected, as the share of EWPA increases, the above parameters decrease; however, the decrease in strength despite the extremely high replacement of aggregate is not dramatic. The decreases in the bulk density, compressive strength, and flexural strength of the individual samples are as follows:

- sample 50/50: $19.3 \%, 0 \%$ and $20.4 \%$ respectively

- sample $70 / 30: 26.8 \%, 0.5 \%$ and $27.8 \%$ respectively

- sample 90/10: $36.6 \%, 7.4 \%$ and $33.3 \%$ respectively

In this context, the specific strength is an intriguing parameter, which increases with increasing proportion of EWPA under compressive stress while remaining in principle the same under flexural stress as the specific strength of the sample without EWPA. The specific compressive and flexural strengths, expressed as a ratio of strength and density, are as follows:

- sample 0/100: $10.18 \mathrm{MPa} / \mathrm{g} / \mathrm{cm}^{3}$ and $2.54 \mathrm{MPa} / \mathrm{g} / \mathrm{cm}^{3}$ respectively

Sičáková, A, Figmigová, E 
- sample 50/50: $12.62 \mathrm{MPa} / \mathrm{g} / \mathrm{cm}^{3}$ and $2.50 \mathrm{MPa} / \mathrm{g} / \mathrm{cm}^{3}$ respectively

- sample 70/30: $13.85 \mathrm{MPa} / \mathrm{g} / \mathrm{cm}^{3}$ and $2.50 \mathrm{MPa} / \mathrm{g} / \mathrm{cm}^{3}$ respectively

- sample 90/10: $14.87 \mathrm{MPa} / \mathrm{g} / \mathrm{cm}^{3}$ and $2.67 \mathrm{MPa} / \mathrm{g} / \mathrm{cm}^{3}$ respectively.

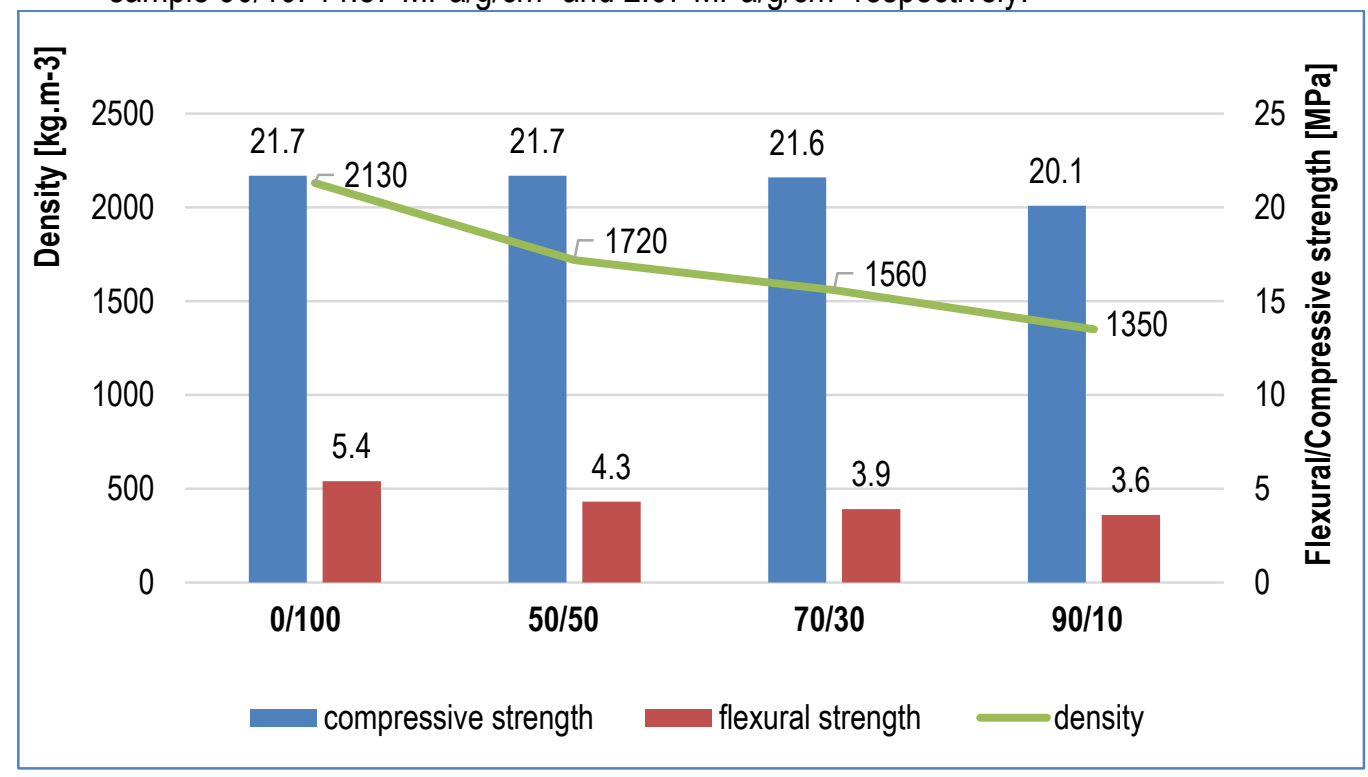

Figure 4 Results of compressive strength, flexural strength and density of samples after 28 days of curing

\subsection{Results of resistance to aggressive actions}

The results of the resistance to physical effects are presented in Tab. 3, and the resistance to chemical effects are presented in Tab. 4, together with the strengths of the control samples (before exposure) for comparison.

Table 3 Compressive and flexural strength of control samples and samples subjected to 25 cycles of physical influences

\begin{tabular}{|c|c|c|c|c|c|c|}
\hline \multirow{2}{*}{$\begin{array}{c}\text { Sample } \\
\text { (EWPA/NA } \\
\text { ratio) }\end{array}$} & \multicolumn{3}{|c|}{$\begin{array}{c}\text { Flexural strength } \\
f_{f}[\mathrm{MPa}]\end{array}$} & \multicolumn{3}{|c|}{$\begin{array}{c}\text { Compressive strength } \\
\mathrm{f}_{\mathrm{c}}[\mathrm{MPa}]\end{array}$} \\
\hline & Control & $\begin{array}{l}\text { Freeze-thaw } \\
\text { exposure }\end{array}$ & $\begin{array}{l}\text { Wet-dry } \\
\text { exposure }\end{array}$ & Control & $\begin{array}{l}\text { Freeze-thaw } \\
\text { exposure }\end{array}$ & $\begin{array}{l}\text { Wet-dry } \\
\text { exposure }\end{array}$ \\
\hline $0 / 100$ & 5.4 & 6.2 & 6.5 & 21.7 & 30.7 & 32.9 \\
\hline $50 / 50$ & 4.3 & 5.2 & 3.3 & 21.7 & 29.5 & 21.1 \\
\hline $70 / 30$ & 3.9 & 4.5 & 2.6 & 21.6 & 29.0 & 17.3 \\
\hline $90 / 10$ & 3.6 & 4.1 & 1.9 & 20.1 & 27.2 & 12.0 \\
\hline
\end{tabular}

Table 4 Compressive and flexural strength of control samples and samples subjected to 60 days to chemical influences

\begin{tabular}{lllllllll}
\hline & \multicolumn{3}{c}{$\begin{array}{c}\text { Flexural strength } \\
\mathrm{f}_{\mathrm{f}}[\mathrm{MPa}]\end{array}$} & & \multicolumn{4}{c}{$\begin{array}{c}\text { Compressive strength } \\
\mathrm{f}_{\mathrm{c}}[\mathrm{MPa}]\end{array}$} \\
$\begin{array}{c}\text { Sample } \\
\text { (EWPA/NA } \\
\text { ratio) }\end{array}$ & Control & $\mathrm{HCl}$ & $\mathrm{MgSO}_{4}$ & $\mathrm{NaOH}$ & Control & $\mathrm{HCl}$ & $\mathrm{MgSO}_{4}$ & $\mathrm{NaOH}$
\end{tabular}

Sičáková, A, Figmigová, $E$ 
Durability study of concrete with Electronic Waste Plastic Aggregate

34.8
20.5
12.8
6.5

- Change in strength - comparison with the results of samples without EWP(0/100):

In Figs. 5 and 6, the percentage change in the strength of samples with EWP after exposure to aggressive environments against samples without EWP (0/100) is shown. Samples with EWP also had lower flexural strength and compressive strength, while the loss increased with increasing amounts of EWP in all cases of action.

Alternating freezing-thawing reduced both the flexural and compressive strengths of samples with EWP by $16 \%-34 \%$ and by $4 \%-11 \%$, respectively, compared to the sample without EWP $(0 / 100)$.

Wet-dry cycles reduced both the flexural and compressive strengths of samples with EWP by $49 \%-71 \%$ and $36 \%-64 \%$, respectively, compared to the sample without EWP $(0 / 100)$. The rate of decrease in strength after wetdry cycles is more pronounced than that after freeze-thaw cycles.

Chemical exposure caused decreases in both the flexural and compressive strengths of samples with EWP by $48 \%-78 \%$ and $31 \%-86 \%$, respectively, compared to the sample without EWP $(0 / 100)$, with the differences between media being essentially minimal. From the viewpoint of increasing the share of EWP, the action of $\mathrm{MgSO}_{4}$ has a milder impact than the other two environments.

Hence, the addition of EWP reduced the durability of the mixtures compared to concrete with only natural aggregates.

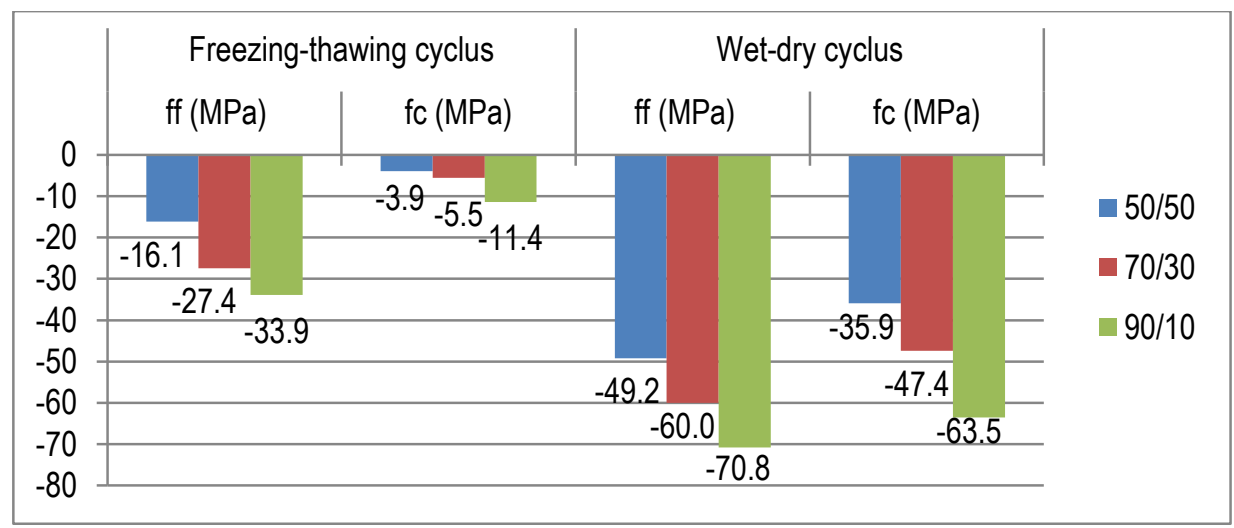

Figure 5 Decrease in flexural $\left(\mathrm{f}_{\mathrm{f}}\right)$ and compressive $\left(\mathrm{f}_{\mathrm{c}}\right)$ strength of control samples and samples after alternating freezing-thawing and alternating wetting-drying, against the sample 0/100 (without EWP) [\%]

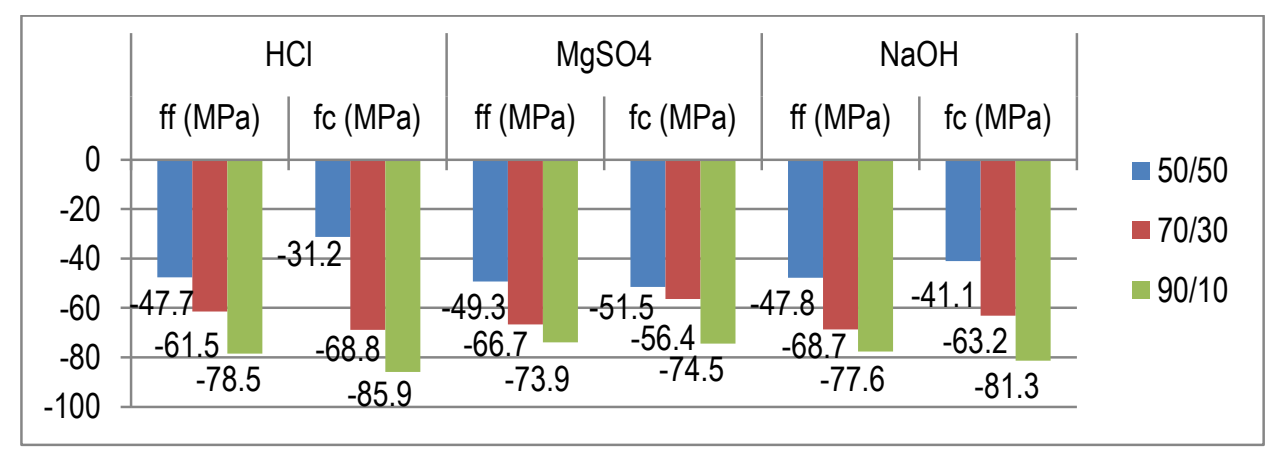

Figure 6 Decrease in flexural $\left(f_{f}\right)$ and compressive $\left(f_{c}\right)$ strength of control samples and samples after chemical exposure, against sample 0/100 (without EWP) [\%] 


\section{- Change in strength - comparison with the results of control samples}

Figs. 7 and 8 show the percentage change in the strength of samples exposed to aggressive influence, compared to the values of the control samples (before exposure).

We can see that the freezing and thawing processes increased the strengths of all samples, including those containing EWP. However, note that these were tested for a relatively small number of cycles (the intention was to keep the same number of cycles as wet-dry to maintain the compatibility of the results). The increase in strength after a few freezing cycles is attributed to the mechanism of continued hydration of the binder, in which the internal hydraulic pressRWSure of ice does not exceed the actual tensile strength of concrete, preventing damage from occurring. Manifestations of frost, depending on the time and number of cycles, were formulated by Wawrencyk and Molendowska [32]. Reliability is defined as the probability of damage to the concrete as a function of time (number of freeze-thaw cycles). This is described for standard mixtures with natural aggregates, and this also seems to be the case for mixtures with EWP. Another aspect may be associated with the development of favorable porosity, which may be helpful. Concrete, for example, does not deteriorate under cyclic freezing if its matrix contains uniformly distributed bubbles with a distance factor of less than $0.02 \mathrm{~cm}$ to keep the concrete intact during frost aggression under severe service conditions, as replicated by Trofimov et al. [33]. It is probable that the destructive effect would manifest itself only after a larger number of cycles, as presented by Kan and Demirbogğa [10]. In their research on mixtures with different proportions of MEPS, all mixtures failed before 300 freeze-thaw cycles; the authors stated that none of them fulfilled the basic requirements of durability. This explains why lightweight concrete is also subject to deterioration due to freeze-thaw cycling.

On the other hand, for samples containing EWP, alternating wetting-drying caused a decrease in strength, the decrease being proportional to the proportion of EWP. The sample without EWP $(0 / 100)$ showed an increase in both strengths, even with this action. Thus, as can be seen, mixtures with EWP are no longer very resistant to the stresses arising from alternating soaking-drying.

Chemical exposure also caused a decrease in the strength of the samples with EWP, while the samples without EWP showed an increase in strength at this stage of the evaluation. As in the case of frost resistance, shortterm chemical deposition does not cause destructive changes to ordinary concrete with natural aggregates $(0 / 100)$. The resistance of the samples deteriorated with an increasing proportion of EWP.

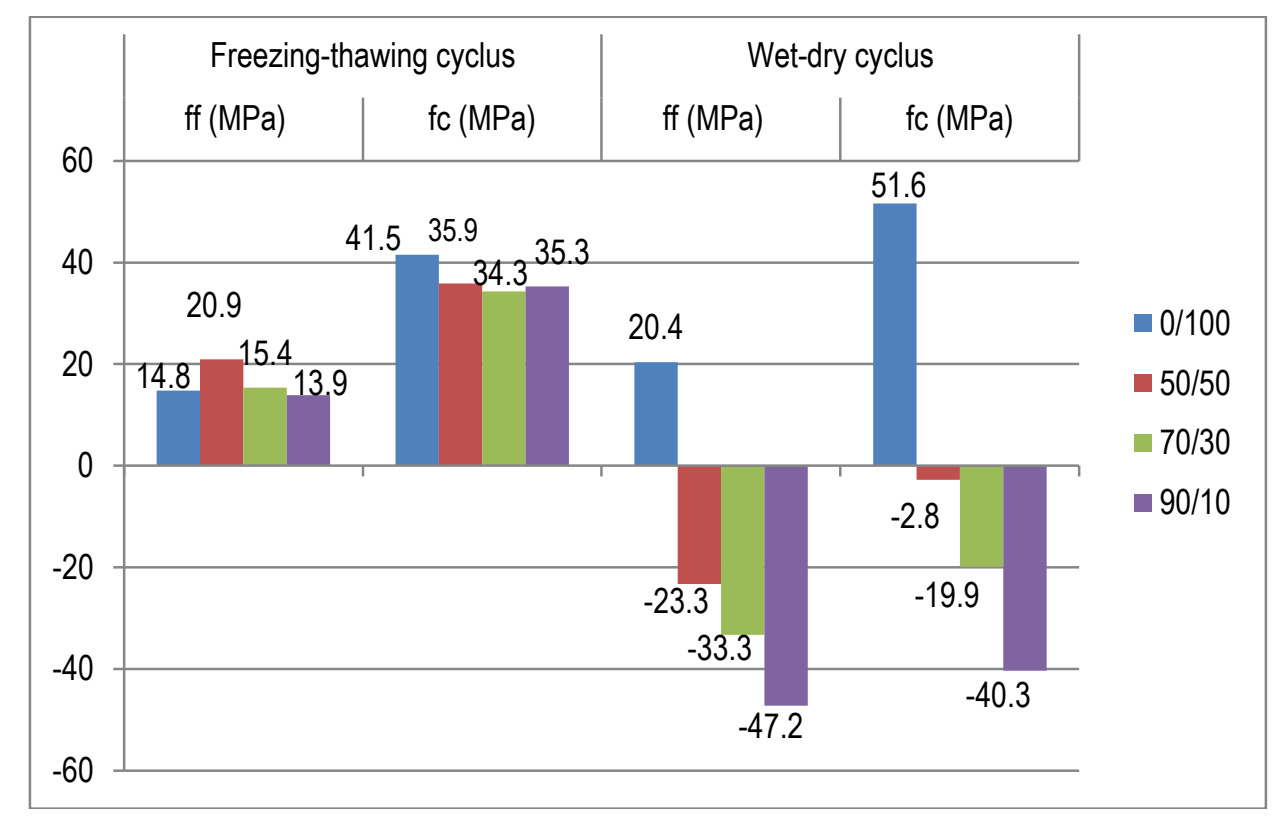

Figure 7 Increase/decrease in flexural (ff) and compressive (fc) strength of samples after alternating freezing-thawing and alternating wetting-drying, against the control samples (before cycling) [\%] 


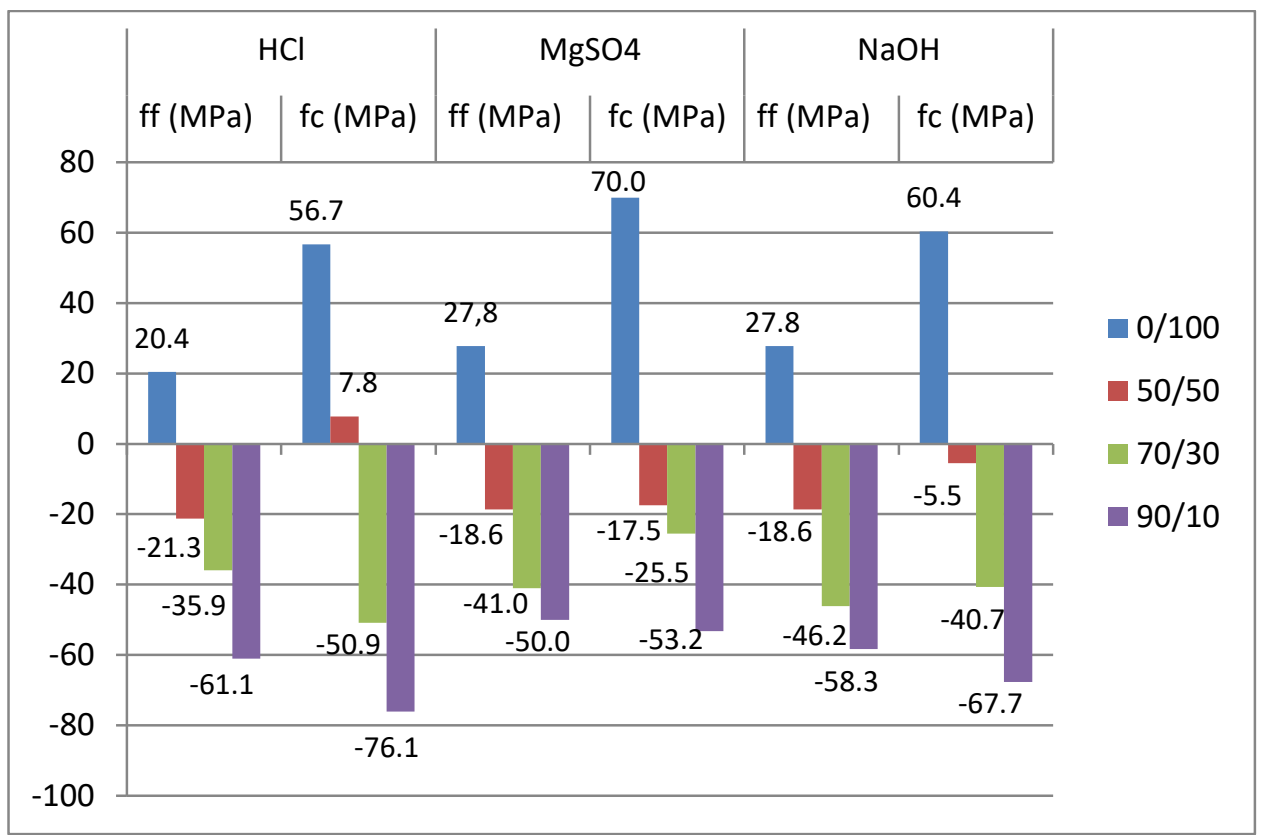

\section{Figure 8 Increase/decrease in flexural $\left(f_{f}\right)$ and compressive $\left(f_{c}\right)$ strength of samples after chemical exposure, against the control samples (before exposure) [\%]}

The decrease in strength with increasing amounts of EWP, either after 28 days of standard curing (before exposure) or after exposure to aggressive influences, can, in this case, be related to aspects resulting from the high content and specific nature of EWP grains (as the binder is constant), and subsequently the quality of the interfacial transition zone (ITZ) in the layer around the EWP.

Even in ordinary concrete, ITZ is considered a critical area; for example, Wu et al. and Scrivener et al. [34, 35] describe ITZ as having higher porosity, oriented deposition, and fewer cement particles (compared to bulk cement matrix) because of the wall effect of aggregates, which plays a critical role in the damage process caused by sulfate attack. Hence, the ITZ microstructure allows the transport of aggressive media more easily. Liu et al. [36] showed that the damage of concrete under sulfate erosion starts to propagate in the ITZ because of the formation of ettringite and gypsum. The concrete ITZ was the first to crack with the corrosion conditions, which was detected at the early stage of corrosion owing to the sparse structure of the ITZ.

As for the PA concretes, Ashwini observed that the failure of concrete occurs owing to the failure of the bond between the cement paste and plastic aggregates [16]. Many authors [15-18] state that as the amount of PA added to the concrete increases, the strength decreases because full adherence between the PA and cement paste cannot be achieved [10]. To confirm this, some authors have presented scanning electron microscopy (SEM) or other micro-analysis of ITZ [21, 37]. Basha et al. identified a de-bonding between the PA and mortar matrix in the SEM images of the PA concrete, which might have contributed to a reduction in the mechanical properties of PA concrete [21]. The smooth surface of the PA and minimal sorptivity of particles affects the ITZ quality, resulting in free water accumulating at the surface of the granules, which may cause a weaker bonding between the PA particles and cement paste [7]. The results of our experiment may reflect this mechanism because, although very low, the same $\mathrm{w} / \mathrm{b}$ was used in all mixtures, which implies that as the proportion of EWP increases, so does the amount of free water. In other words, the effective $w / b$ increased.

Belmokaddem et al. observed large air bubbles in cement pastes prepared with plastic aggregates [37]. According to Hannawi et al. [38], the apparent porosity and water absorption increased with increasing PA content. Albano et al. reported higher water absorption for concrete containing PET aggregates than for concrete containing only natural aggregate [6]. Water absorption further increased with increasing PA content in the concrete. Choi et al. and Akçaözoğlu et al. [22, 39] reported similar results. This fact can be responsible for low chemical resistance, considering a well-known opinion also presented by [19], which tests such as water absorption, gas permeability, and chloride permeability measurement can provide information on the vulnerability of concrete to the ingress of deleterious chemical species. 
From a practical viewpoint, it may be useful to predict the durability of mixtures with high EWP content. For this purpose, the relationships between the strength of samples before and after aggressive exposure were sought to obtain relevant functions; these are presented in Fig. 9. The relationships had an $\mathrm{R}^{2}=0.6141$ and 0.9909 for compressive and flexural strength, respectively. Coefficients of determination above 0.5 , are generally considered highly reliable in predicting the dependent variables, while values above 0.8 , representing very high reliability. All the results presented in this article, except for the freeze-thaw resistance results (considered to be of low informative value owing to the low number of cycles) were included in the dependency evaluation. The following relationships were found to predict durability in accordance with the 28-day strength values:

- Function for prediction of compressive strength: exponential: $\mathrm{f}_{\mathrm{c}}=9.10^{-6} e^{0.6768 f_{c 28}}$

- $\quad$ Function for prediction of flexural strength: linear $\mathrm{f}_{\mathrm{f}}=2.8011 \mathrm{f}_{\mathrm{f} 28}-8.5196$

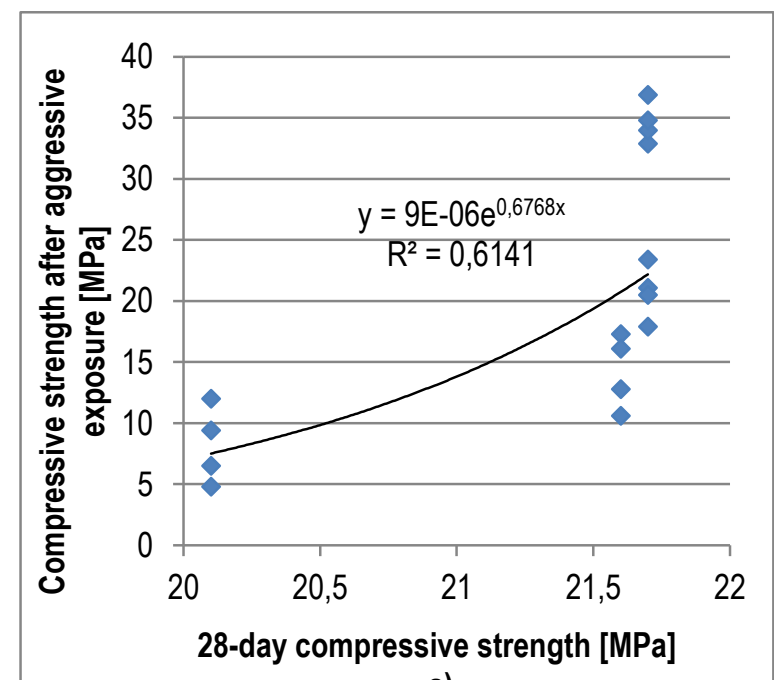

a)

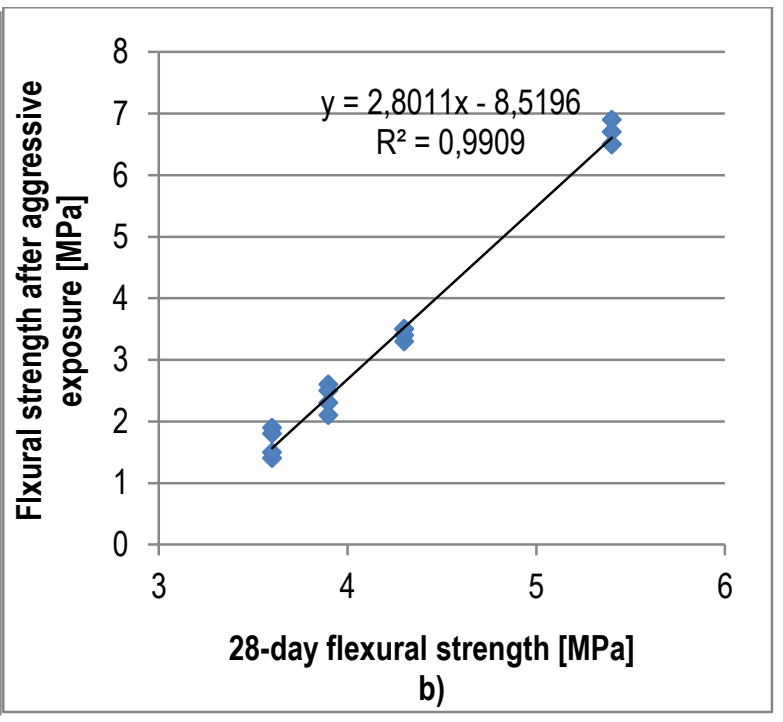

b)

Figure 9 Function for prediction of durability in accordance with 28-day values of strength: a) Function for prediction of compressive strength; b) Function for prediction of flexural strength

\section{CONCLUSION}

Concrete mixtures with EWP, which were applied as $50 \%, 70 \%$, and $90 \%$ replacement for natural aggregates, were tested. The same volume ratio of aggregate and binder was maintained $\left(a: b=0.6: 0.4 \mathrm{~m}^{3}\right)$, as well as the same water-to-binder ratio $w / b=0.35$. In relation to the compressive and flexural strength after 28 days of hardening, the durability against physical (freeze-thaw resistance and wet-dry resistance; 25 cycles) and chemical $\left(\mathrm{HCl}, \mathrm{MgSO}_{4}, \mathrm{NaOH} ; 60\right.$ days of exposure) aggressive influences were determined. The results obtained for the samples with EWP are summarized as follows:

- With increasing amounts of EWPA, the 28-day compressive and flexural strengths decreased, but the differences were not significant. Even with the highest amount of EWPA (90/10) and the least suitable grain size distribution of the aggregate (20.1 MPa—compressive strength and $3.6 \mathrm{MPa}$-flexural strength), the achieved strengths reach usable levels for construction.

- As the amount of EWPA increases, the specific compressive strength increases (strength-to-density ratio).

- Although the strength values after 28 days of curing are of good performance, satisfactory durability results have not been obtained.

- With an increasing share of EWP, the durability of mixtures against physical influences deteriorates, while the rate of decrease in strength after wet-dry cycles is more pronounced compared to the effect of freezing cycles.

- With an increasing share of EWP, the durability of mixtures against chemical influences deteriorates, while the differences between the individual acting media $\left(\mathrm{HCl}, \mathrm{MgSO}_{4}, \mathrm{NaOH}\right)$ are minimal. 
- In terms of a comprehensive evaluation of the experiment, concrete with the ratio EWP/NA $=50 / 50$ has the greatest potential, while it can be specified according to [21] as lightweight-low strength concrete (with a density of $1720 \mathrm{kgm}^{-3}, 21.7 \mathrm{MPa}$ of 28-day compressive strength, and $4.3 \mathrm{MPa}$ of 28-day flexural strength).

Although our results, as well as those of many authors, appear less positive measures must be taken, if possible, in view of the need to increase the recycling of plastic waste. For use in concrete, which can then be used on lightweight non-load-bearing elements, such as a floor insulation layer, should cover two directions:

I. Consider the technical limits of this material and in relation to them:

- Appropriately specify the achievable functional properties of concrete and find application possibilities for which PA can be beneficial. Perspective parameters include density, the modulus of elasticity, thermal insulation properties, or specific strength. As presented by Albano et al. [6], the inclusion of plastic (PET) implies defects in the internal structure of the concrete, resulting in strength and a decrease in stiffness; however, this behavior can be profitable when some ductility of the material is required. Maher Al-Tayeb et al. [40] found concrete with plastic waste to be stronger and more energy-absorbing under impact loading than under static loading.

- Defined an acceptable level of PA content in cement mixtures to achieve the required values of these parameters.

II. Improves the quality of PA by appropriate modification of the surface or optimization of the composition of the mixture; with increasing proportion of PA in the mixture, there is an increase in problematic ITZ because of its smooth surface, low adhesion to the binder, and virtually zero absorbency with consequent increase in free water content. This must be considered when optimizing the composition of the mixture and strictly applying the expression of the 'effective' $w / b$, that is, the amount of water available for the binder. Additionally, plastic is a hydrophobic material that can limit the hydration of cement. Some treatment processes would be useful in helping PA increase its performance. Chemical treatment of the surface of plastic particles with $\mathrm{Ca}(\mathrm{ClO})_{2}$ was reported by Lee et al. [41] to improve the strength owing to improvements in the bond between the cement paste and plastic aggregates. The targeted use of powdery mineral admixtures could also be useful, as presented by Lakshmi and Nagan [17] for fly ash.

\section{Acknowledgment}

This research has been carried out within the project of Slovak Scientific Grant Agency VEGA (Grant No. 1/0524/18) "Effective use of alternative aggregate of lower quality through modern concrete preparation techniques".

\section{References}

[1] Almeshal, I. et al. 2020: Use of recycled plastic as fine aggregate in cementitious composites: A review, Construction and Building Materials, 253, 119146. https://doi.org/10.1016/i.conbuildmat.2020.119146

[2] Bui, N.K.; Satomi, T.; Takahashi, H. 2018: Recycling woven plastic sack waste and PET bottle waste as fiber in recycled aggregate concrete: An experimental study, Waste Management, 78, pp. 79-93. https://doi.org/10.1016/i.wasman.2018.05.035

[3] Al-Hadithi, A.I.; Hilal, N. N. 2016: The possibility of enhancing some properties of self-compacting concrete by adding waste plastic fibers, Journal of Building Engineering, 8, pp. 20-28. https://doi.org/10.1016/j.jobe.2016.06.011

[4] Pešić, N. et al. 2016: Mechanical properties of concrete reinforced with recycled HDPE plastic fibres, Construction and Building materials, 115, pp. 362-370. https://doi.org/10.1016/i.conbuildmat.2016.04.050

[5] Safi, B. et al. 2013: The use of plastic waste as fine aggregate in the self-compacting mortars: Effect on physical and mechanical properties, Construction and Building Materials, 43, pp. 436-442. https://doi.org/10.1016/i.conbuildmat.2013.02.049

[6] Albano, C. et al. 2009: Influence of content and particle size of waste pet bottles on concrete behavior at different w/c ratios, Waste Management, 29 (10), pp. 2707-2716. https://doi.org/10.1016/j.wasman.2009.05.007

[7] Kou, S. C. et al. 2009: Properties of lightweight aggregate concrete prepared with PVC granules derived from scraped PVC pipes, Waste Management, 29 (2), pp. 621-628. https://doi.org/10.1016/j.wasman.2008.06.014

Sičáková, A, Figmigová, $\mathrm{E}$ 
[8] Gregorova, V.; Ledererova, M.; Stefunkova, Z. 2017: Investigation of Influence of Recycled Plastics from Cable, Ethylene Vinyl Acetate and Polystyrene Waste on Lightweight Concrete Properties, Procedia Engineering, 195, pp. 127-133. https://doi.org/10.1016/j.proeng.2017.04.534

[9] Yang, S. et al. 2015: Properties of self-compacting lightweight concrete containing recycled plastic particles, Construction and Building Materials, 84, pp. 444-453. https://doi.org/10.1016/i.conbuildmat.2015.03.038

[10] Kan, A.; Demirboğa, R. 2009: A novel material for lightweight concrete production, Cement and Concrete Composites, 31 (7), pp. 489-495. https://doi.org/10.1016/j.cemconcomp.2009.05.002

[11] Wu, H., Liu, C., Shi, S., Chen, K. 2020: Experimental Research on the Physical and Mechanical Properties of Concrete with Recycled Plastic Aggregates, Journal of Renewable Materials, 8 (7), pp. 727-738. https://doi.org/10.32604//irm.2020.09589

[12] Mary Treasa Shinu, N.M.; Needhidasan, S. 2020: An experimental study of replacing conventional coarse aggregate with E-waste plastic for M40 grade concrete using river sand, Materials Today: Proceedings, 22 (Part 3), pp. 633-638. https://doi.org/10.1016/j.matpr.2019.09.033

[13] Santhanam, N.; Ramesh, B.; Pohsnem, F.K. 2020: Concrete blend with E-waste plastic for sustainable future, Materials Today: Proceedings, 22 (Part 3), pp. 959-965. https://doi.org/10.1016/i.matpr.2019.11.204

[14] Suleman, S.; Needhidasan, S. 2020: Utilization of manufactured sand as fine aggregates in electronic plastic waste concrete of M30 mix, Materials Today: Proceedings, 33 (Part 1), pp. 1192-1197. https://doi.org/10.1016/i.matpr.2020.08.043

[15] Ramesh Kumar, G.; Santhosh, K.S.; Bharani S. 2021: Influence of E-waste on properties of bituminous mixes, Materials Today: Proceedings, 32 (Part 2), pp. 2719-2724. https://doi.org/10.1016/j.matpr.2020.08.539

[16] Ashwini Manjunath, BT. 2016: Partial replacement of e-plastic waste as coarse-aggregate in concrete, Procedia Environmental Sciences, 35, pp. 731-739. https://doi.org/10.1016/i.proenv.2016.07.079

[17] Lakshmi, R.; Nagan, S. 2010: Studies on Concrete containing E plastic waste, Studies on Concrete containing E plastic waste, 1 (3), pp. 270-281.

[18] Awoyera, P.O.; Adesina A. 2020: Plastic wastes to construction products: Status, limitations and future perspective, Case Studies in Construction Materials, 12, e00330. https://doi.org/10.1016/j.cscm.2020.e00330

[19] Saikia, N.; de Brito, J. 2012: Use of plastic waste as aggregate in cement mortar and concrete preparation: A review, Construction and Building Materials, 34, pp. 385-401. https://doi.org/10.1016/i.conbuildmat.2012.02.066

[20] Slovak Office of Standards, Metrology and Testing. 206+A1: Concrete. Specification, performance, production and conformity; Slovak Office of Standards, Metrology and Testing: Bratislava, Slovakia, 2017.

[21] Basha, S.I; Ali, M.R.; Al-Dulaijan, S.U.; Maslehuddin, M. 2020: Mechanical and thermal properties of lightweight recycled plastic aggregate concrete, Journal of Building Engineering, 32, 101710. https://doi.org/10.1016/i.jobe.2020.101710

[22] Choi, Y.W.; Moon, D.J.; Kim, Y.J.; Lachemi, M. 2009: Characteristics of mortar and concrete containing fine aggregate manufactured from recycled waste polyethylene terephthalate bottles, Construction and Building Materials, 23 (8), pp. 2829-2835. https://doi.org/10.1016/i.conbuildmat.2009.02.036

[23] Slovak Office of Standards, Metrology and Testing. STN EN 12390-2: Testing hardened concrete. Part 2: Making and curing specimens for strength tests; Slovak Office of Standards, Metrology and Testing: Bratislava, Slovakia, 2020

[24] Slovak Office of Standards, Metrology and Testing. STN EN 12390-7: Testing hardened concrete. Part 7: Density of hardened concrete; Slovak Office of Standards, Metrology and Testing: Bratislava, Slovakia, 2020

[25] Slovak Office of Standards, Metrology and Testing. STN EN 196-1: Methods of testing cement. Part 1: Determination of strength; Slovak Office of Standards, Metrology and Testing: Bratislava, Slovakia, 2019

[26] Tang, L.; Petersson P.-E. 2004: Slab test: Freeze/thaw resistance of concrete - Internal deterioration, Materials and Structures, 37, pp. 754-759. https://doi.org/10.1007/BF02480522

[27] ASTM C666 / C666M-15, Standard Test Method for Resistance of Concrete to Rapid Freezing and Thawing, ASTM International, West Conshohocken, PA, 2015.

[28] Guo, J.-J. et al. 2019: Effect of Dry-Wet Ratio on Properties of Concrete under Sulfate Attack, Materials, 12 (17), 2755. https://doi.org/10.3390/ma12172755

[29] He, R. et al. 2020: Damage mechanism and interfacial transition zone characteristics of concrete under sulfate erosion and Dry-Wet cycles, Construction and Building Materials, 255, 119340. https://doi.org/10.1016/i.conbuildmat.2020.119340 
[30] Tang, J. et al. 2018. Development of properties and microstructure of concrete with coral reef sand under sulphate attack and drying-wetting cycles, Construction and Building Materials, 165, pp. 647-654. https://doi.org/10.1016/i.conbuildmat.2018.01.085

[31] Sutrisno, W.; Suprobo, P.; Wahyuni, E.; Iranata, D. 2016: Experimental Test of Chloride Penetration in Reinforced Concrete Subjected to Wetting and Drying Cycle, Applied Mechanics and Materials, 851, pp. 846851. https://doi.org/10.4028/www.scientific.net/AMM.851.846

[32] Wawrzeńczyk, J.; Molendowska, A. 2017: Evaluation of concrete resistance to freeze-thaw based on probabilistic analysis of damage, Procedia Engineering, 193, pp. 35-41. https://doi.org/10.1016/j.proeng.2017.06.183

[33] Trofimov, B.Y.; Kramar, L. Y.; Schuldyakov, K. V. 2017: On Deterioration Mechanism of Concrete Exposed to Freeze-Thaw Cycles, IOP Conference Series: Materials Science and Engineering, 262, 012019.

[34] Wu, K.; et al. 2016: Microstructural characterization of ITZ in blended cement concretes and its relation to transport properties, Cement and Concrete Research, 79, pp. 243-256. https://doi.org/10.1016/i.cemconres.2015.09.018

[35] Scrivener, K.L.; Crumbie, A.K.; Laugesen, P. 2004: The interfacial transition zone (ITZ) between cement paste and aggregate in concrete, Interface Science, 12, pp. 411-421. https://doi.org/10.1023/B:INTS.0000042339.92990.4c

[36] Liu, Z.; De Schutter, G.; Deng, D.; Yu, Z. 2010: Micro-analysis of the role of interfacial transition zone in "salt weathering" on concrete, Construction and Building Materials, 24 (11), pp. 2052-2059. https://doi.org/10.1016/i.conbuildmat.2010.04.053

[37] Belmokaddem, M.; Mahi, A.; Senhadji, Y.; Pekmezci, B.Y. 2020: Mechanical and physical properties and morphology of concrete containing plastic waste as aggregate, Construction and Building Materials, 257, 119559. https://doi.org/10.1016/i.conbuildmat.2020.119559

[38] Hannawi, K.; Kamali-Bernard, S.; Prince, W. 2010: Physical and mechanical properties of mortars containing PET and PC waste aggregates, Waste Management, 30 (11), pp. 2312-2320. https://doi.org/10.1016/j.wasman.2010.03.028

[39] Akçaözoğlu, S.; Atis, C.D.; Akçaözoğlu, K. 2010: An investigation on the use of shredded PET waste bottles as aggregate in lightweight concrete, Waste Management, 30 (2), pp. 285-290. https://doi.org/10.1016/i.wasman.2009.09.033

[40] Maher Al-Tayeb, M.; Hanafi, I.; Mahmoud, R.; Tayeh, B.A. 2019: Effect of partial replacement of sand by plastic waste on impact resistance of concrete: experiment and simulation, Structures, 20, pp. 519-526. https://doi.org/10.1016/i.istruc.2019.06.008

[41] Lee, Z.H et al. 2019: Modification of waste aggregate PET for improving the concrete properties, Advances in Civil Engineering, Article ID 6942052. https://doi.org/10.1155/2019/6942052

Please cite this article as: Sičáková, A.; Figmigová, E.: Durability study of concrete with Electronic Waste Plastic Aggregate, Electronic Journal of the Faculty of Civil Engineering Osijek-e-GFOS, 2021, 22, pp. 56-69, https://doi.org/10.13167/2021.22.5 